Bio - grafía. Escritos sobre la Biología y su Enseñanza. ISSN 2027-1034

Edición Extraordinaria. p.p. $1263-1270$

Memorias del IX Encuentro Nacional de Experiencias en Enseñanza de la Biología y la Educación Ambiental. IV Congreso Nacional de Investigación en Enseñanza de la Biología.

\title{
IMPORT ANCIA QUE LOS ADOLESCENTES OTORGAN A PREVENIR INFECCIONES DE TRANSMISIÓN SEXUAL (ITS) DESDE UNA COMPRENSIÓN DE LOS VIRUS
}

\section{IMPORT ANCE ADOLESCENTS GIVE TO PREVENT SEXUALLY TRANSMITTED INFECTIONS (STI) FROM THE UNDERST ANDING OF VIRUSES}

\author{
Lina María Bejarano Rivera' \\ Mayra Alejandra Ramírez Díaz ${ }^{1}$
}

\section{RESUMEN}

El presente artículo da cuenta de una experiencia pedagógica realizada con estudiantes de grado décimo del Colegio Distrital El Salitre Suba, en la que se realiza un desarrollo conceptual acerca de los organismos víricos con el fin de promover el cuidado de su salud sexual entorno a las ITS, tomando como eje: el VIH y el VPH. EI trabajo se realiza bajo el marco de la investigación cualitativa, teniendo en cuenta tres estrategias de recolección de datos: la entrevista, los cuestionarios y el diario del profesor. De acuerdo a los resultados obtenidos, se evidencia que desde la comprensión de los virus, los estudiantes logran señalar características propias de estos microorganismos como la necesidad una célula para replicarse, capacidad de modificar su material genético, entre otras a nivel reproductivo y morfológico; además de su capacidad patogénica. Por lo que desde allí reconocen la importancia del cuidado respecto a su salud sexual (ITS), relacionado con aquellas estrategias de prevención, en las que destacan la comunicación con la pareja y el uso del condón, donde esta primera involucra una importancia por el propio cuerpo y el de la pareja.

PALABRAS CLAVE: infecciones de transmisión sexual, virus

\section{ABSTRACT}

The present article it's about a pedagogical experience realized with students of tenth grade from Colegio Distrital EI Salitre Suba, in which a conceptual development is realized about the viral organisms with the purpose to promote the care of his sexual health around the ITS, based on HIV and HPV. The work is done under the framework of qualitative research, taking into account three strategies of data collection: the interview, the questionnaires and the teacher's diary. According to the results obtained, it is evident that from the understanding of the virus, students are able to point out characteristics of these microorganisms, such as their need for a cell to replicate, the ability to modify their genetic material, among others in the reproductive and morphological level; in addition to its pathogenicity. Therefore, they recognize the importance of care for their sexual health (STI), related to prevention strategies, in which they emphasize communication with the couple and the use of condoms, where the first one involves an importance for one's own body and that of the couple.

\footnotetext{
${ }^{1}$ Estudiante de Licenciatura en Bilogía de la Universidad Distrital Francisco José de Caldas
} 
Bio - grafía. Escritos sobre la Biología y su Enseñanza. ISSN 2027-1034

Edición Extraordinaria. p.p. $1263-1270$

Memorias del IX Encuentro Nacional de Experiencias en Enseñanza de la Biología y la Educación Ambiental. IV Congreso Nacional de Investigación en Enseñanza de la Biología.

KEYWORDS: sexually transmitted infections, virus

\section{INTRODUCCIÓN}

En Colombia y a nivel mundial, especialmente los países en vía de desarrollo poseen un índice elevado de la presencia de enfermedades de transmisión sexual en adolescentes y jóvenes, las cuales se encuentran principalmente relacionadas con un inicio temprano de la vida sexual y las prácticas riesgosas o inseguras que deciden asumir en ocasiones, esto, sin tener una conciencia o responsabilidad por sí mismo y por la pareja. Además, el tener una vida sexual activa a edad temprana, abre la posibilidad de tener un mayor número de parejas sexuales y así una mayor exposición a contraer TS o ETS (Mendoza, Arias, Pedroza, Micolta, Ramírez, Cáceres, López, Núñez \& Acuña, 2012).

De tal manera que las ITS o ETS, junto con embarazos adolescentes y otras problemáticas cotidianas hacen de la educación sexual una necesidad en la escuela, que puede no solamente amortiguar dichas problemáticas de salud pública en la sociedad sino que logra convertirse en un espacio para la constitución de la persona, desde el análisis y la capacidad de decidir en las prácticas sexuales (Roa \& Osorio, 2015).

Sin embargo la educación sexual integral resulta ser un tema muy amplio, por lo que para el presente artículo se toma desde la salud sexual, en la que se encuentra una preocupación por los índices de contagio que existen de TS o ETS y por ende se pretende evidenciar posibles acciones de autocuidado en los adolescentes de grado décimo del Colegio distrital el Salitre Suba, que se encuentran entre los 14 y 17 años de edad.

Según Meinardi, Revel, Godoy, Iglesias, Rodríguez, Plaza \& Bonan (2008) en la actualidad, abordar este tema tiene como supuesto que los mismos individuos deben ser capaces de formar un criterio de manera voluntaria, el cual, les permita decidir si admiten o rechazan determinados riesgos, en este caso la exposición ante una ITS o ETS, lo anterior, mediado por una presentación de información sustanciosa como estrategia de enseñanza. De manera que el reto actual en la educación para la salud es pasar de un plano informativo-preventivo a un plano de modelación-modificación, que permita la promoción de actitudes y toma de decisiones informadas por parte del estudiantado.

De tal forma que el presente trabajo no se limita a dar unas pautas sino a encaminar a los adolescentes a una reflexión y conciencia de la problemática, ya que como menciona Raimundo \& Verdura (2010), en un estudio referente a los conocimientos sobre VPH en secundaria, los estudiantes suelen desconocer en su mayoría los métodos de prevención con respecto al VPH, aunque, algunos destacan el uso del preservativo como una barrera para ello, pero desconocen cómo se manifiesta la infección y sus consecuencias, e incluso existe un desconocimiento parcial o casi total con relación a qué organismo es el VPH, ya que la mayoría lo reconocen como una bacteria u hongo, y muy pocos lo catalogan como virus.

Durante la práctica pedagógica se realizó el desarrollo del concepto virus, aproximándose a la morfología, composición y reproducción de estos organismos 
Bio - grafía. Escritos sobre la Biología y su Enseñanza. ISSN 2027-1034

Edición Extraordinaria. p.p. $1263-1270$

Memorias del IX Encuentro Nacional de Experiencias en Enseñanza de la Biología y la Educación Ambiental. IV Congreso Nacional de Investigación en Enseñanza de la Biología.

desde infecciones de transmisión sexual producidas por microorganismos como el VIH (Virus de inmunodeficiencia humana) y el VPH (Virus del papiloma humano), facilitando la comprensión conceptual del tema y de las implicaciones que tiene contraer una ITS a nivel personal y en la relación con el otro.

En pertinencia es preciso mencionar que la enseñanza de microorganismos como los virus ha estado orientada a relacionar su forma de reproducción con la capacidad que tiene el virus de propagarse e infectar a las personas por medio de prácticas de laboratorio haciendo uso de analogías con sustancias en tubos de ensayo como lo demuestran Boronat \& López (2014).

Por otro lado la enseñanza de este concepto en la escuela, se encuentra que es un concepto que se aborda desde las clases de microbiología que van orientadas principalmente a la importancia ecológica de estos organismos, a reconocer que no resultan dañinos ni para el hombre ni para el ambiente (Rozo, 2011) y a plantearse prácticas de laboratorio como herramientas para hacer del aprendizaje de estos temas algo significativo, entendiendo esto, por medio de una encuesta que se realiza a estudiantes, quienes esperan que el aspecto experimental en estos temas aumente (Antonio \& Vallejo, 2016).

\section{METODOLOGÍA}

El presente trabajo se encuentra apoyado por el diseño e implementación de una Unidad Didáctica (Fonseca, 2015), en la que se desarrolló desde un enfoque de aprendizaje significativo la conceptualización de virus, en el curso 1004 del Colegio Distrital el Salitre, ubicado en Bogotá, con estudiantes en edades que oscilan entre los 14 y 17 años, pertenecientes al estrato 2 y 3 .

Con la mencionada población se desarrolla una investigación de carácter cualitativo, donde se permiten abordar problemas del entorno cotidiano desde un proceso interpretativo de indagación (Vasilachis, Ameigeras, Chenobilsky, Giménez, Mallimaci, Mendizábal, Neiman, Quaranta, \& Soneira, 2006).

Para el desarrollo y obtención de datos en la presente investigación, se tienen en cuenta las estrategias que plantea la investigación cualitativa para ello, por lo que se decide emplear la entrevista, los cuestionarios y el diario del profesor. Donde la entrevista resulta ser semiestructurada, los cuestionarios constan de preguntas que van orientadas a la relación Virus-ITS; y finalmente, el diario del profesor, que según mencionan Porlán y Martín (1991) es un instrumento que permite analizar y a partir de ello reflexionar acerca de la práctica pedagógica, permitiendo establecer conclusiones que llevan a la toma de decisiones durante la experimentación en el aula.

\begin{tabular}{|l|l|}
\hline \multicolumn{1}{|c|}{ FASES } & \multicolumn{1}{c|}{ DESCRIPCION } \\
\hline Fase 1: Conceptualización & $\begin{array}{l}\text { Ideas Previas de los estudiantes } \\
\text { Desarrollo conceptual de los virus (Qué son, morfología } \\
\text { y reproducción) a partir del VIH y VPH }\end{array}$ \\
\hline
\end{tabular}


Bio - grafía. Escritos sobre la Biología y su Enseñanza. ISSN 2027-1034

Edición Extraordinaria. p.p. 1263 - 1270

Memorias del IX Encuentro Nacional de Experiencias en Enseñanza de la Biología y la Educación Ambiental. IV Congreso Nacional de Investigación en Enseñanza de la Biología.

\begin{tabular}{|l|l|}
\hline $\begin{array}{l}\text { Fase 2: introducción a las } \\
\text { ITS }\end{array}$ & $\begin{array}{l}\text { Se toma en cuenta las ideas previas del estudiantado, } \\
\text { se define ITS/ETS } \\
\text { Espacio de diálogo: contagio de una ITS, consecuencias } \\
\text { personales de estas patologías, formas de prevención } \\
\text { Propuestas de campañas preventivas por los } \\
\text { estudiantes con elementos de redes sociales } \\
\text { Presentación vídeo con otras ITS producidas por virus, } \\
\text { formas de prevención e imágenes de los agentes } \\
\text { patógenos posentado por parte de los } \\
\text { Resumen del video presentado } \\
\text { estudiantes }\end{array}$ \\
\hline Fase 3: Culminación & $\begin{array}{l}\text { Desarrollo de un cuestionario final con preguntas } \\
\text { conceptuales relacionadas con VIH y VPH y sobre } \\
\text { métodos e importancia de prevención de ITS } \\
\text { Simultáneamente permitiendo a los estudiantes } \\
\text { expresar sus opiniones, preguntas y entablar diálogo } \\
\text { con sus compañeros sobre el tema } \\
\text { Socialización a nivel de curso y conclusión de las } \\
\text { actividades }\end{array}$ \\
\hline
\end{tabular}

Tabla 1. Fases de desarrollo de la experiencia pedagógica

\section{RESULTADOS Y DISCUSIÓN}

En un comienzo los estudiantes señalan que el VIH y el VPH son enfermedades de transmisión sexual, como se detalla: "El VIH es una enfermedad de transmisión sexual y se contagia de varias formas". "El VPH solo le da a las mujeres existe una vacuna que afecta el sistema reproductor femenino". Sin embargo no mencionan que células del cuerpo afectan y no hacen una distinción entre ITS y ETS.

Luego de una conceptualización del tema, logran establecer la diferencia ITS/ETS citando la siguiente frase "El VIH es el camino al sida" "el sida es la enfermedad, pues es la etapa avanzada, mientras que el VIH no muestra síntomas claros al inicio ya que aparece casi después de 10 años", que se encuentra acorde con lo que obtienen Páez y García (2015), pues en la tercera categoría que proponen como enunciación de ITS y ETS, un estudiante señala que

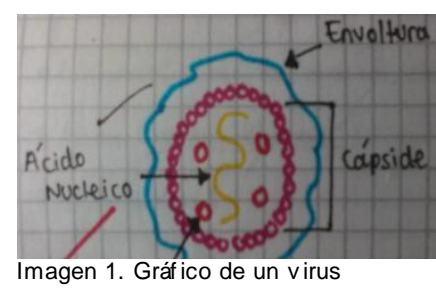
inicialmente se genera una infección y luego se produce la enfermedad.

El desarrollo conceptual se inicia con qué son los virus y su morfología, por lo que los estudiantes logran plasmar algunas partes clave de estos organismos, entre las que se encuentran la cápside, la envoltura, y el material genético 
Bio - grafía. Escritos sobre la Biología y su Enseñanza. ISSN 2027-1034

Edición Extraordinaria. p.p. $1263-1270$

Memorias del IX Encuentro Nacional de Experiencias en Enseñanza de la Biología y la Educación Ambiental. IV Congreso Nacional de Investigación en Enseñanza de la Biología.

(Imagen 1), aunque en su mayoría olvidan estructuras de los virus como las espículas que hacen presencia en el caso del virus del $\mathrm{VIH}$.

A su vez establecen como características morfológicas tales como tamaño y particularidades en su estructura, tienen implicaciones en el contagio de ITS, además de plantearse por qué tiene una importancia prevenir estas patologías cuando se reconocen estos organismos, esto, evidenciándose en afirmaciones como: "Son muy pequeños y no pueden ser vistos con microscopios, por lo que no se detectan fácil, se puede estar infectado y no saberlo como pasa con el VIH". "Porque puedes comprender lo fuertes que son por su estructura, como pasa con el VIH que tiene dos cápsides y una envoltura, lo que hace que sean muy fuertes $y$ difíciles de tratar y exterminar con vacunas y tratamientos".

Con relación a esta última, también se observó que según los estudiantes no solo la morfología

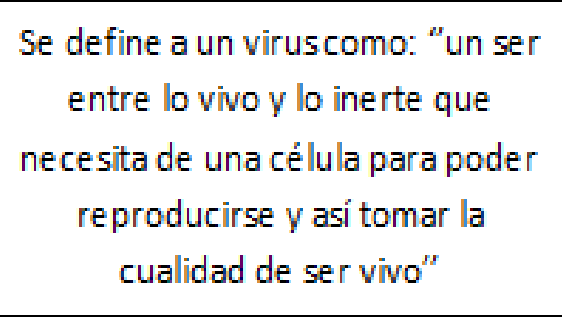

Imagen 2. Definición de virus en mapa conceptual determina la complejidad o "fortaleza" del virus, también lo es la capacidad de estos organismos de generar cambios en su material genético: "Porque saber de ellos te deja entender

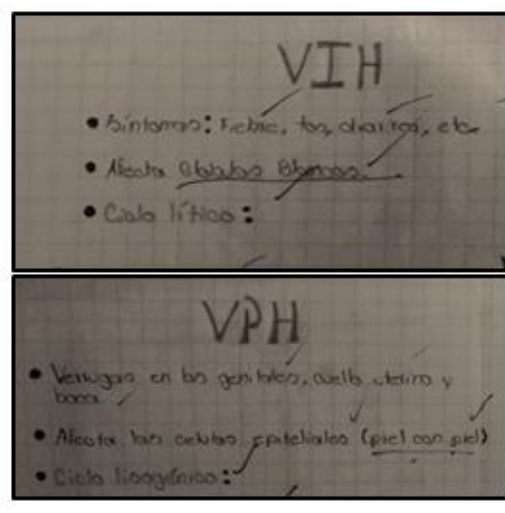

Imagen 3. Cuadro comparativo VIH/VPH cómo actúan al interior de tu cuerpo, además porque a pesar de que no son seres vivos pueden hacer mucho daño pues ellos mutan, así que pueden cambiar rápidamente y hacerse fuertes"

En relación con las características de ciclo reproductivo, se obtiene que los estudiantes reconocen que estos organismos requieren para su reproducción una célula hospedera (Imagen 2) y la identifican para cada uno de los virus (ITS) eje, VIH y VPH (Imagen 3), donde el primero afecta los glóbulos blancos, por lo que se ve comprometido el sistema inmunológico del individuo al que infecta, mientras que el segundo se introduce en células epiteliales y genera verrugas en la persona. Considerando que dicha condición de los virus los convierte en organismos complejos, ya que afectan directamente a la célula y a su vez pueden generar estrategias dentro de ella para continuar infectando, viéndose reflejado en la afirmación que realiza un estudiante: "porque ellos usan una célula para reproducirse entonces cuando estas infectado no puedes matar al virus o a veces el virus se camufla dentro de la célula y el sistema inmune no lo puede ver como pasa con el VIH y así lo contamina".

Por otro lado esto se encuentra relacionado a que su comprensión los lleva a pensar que en cierto momento ellos pueden estar infectados y no saberlo (caso $\mathrm{VIH}$ ), induce a una necesidad de no realizar prácticas riesgosas, como ejemplo el no uso de condón.

Otro aspecto a mencionar es el cómo comprenden el tipo de ciclo reproductivo y la relación que logran establecer con las $\Pi S$, en correspondencia con los ciclos, la diferenciación que plantean es: "Ciclo Lítico: El virus penetra a la célula y se 
Bio - grafía. Escritos sobre la Biología y su Enseñanza. ISSN 2027-1034

Edición Extraordinaria. p.p. 1263 - 1270

Memorias del IX Encuentro Nacional de Experiencias en Enseñanza de la Biología y la Educación Ambiental. IV Congreso Nacional de Investigación en Enseñanza de la Biología.

reproduce dentro de ella. Ciclo lisogénico: El virus infecta a la célula e inyecta el material genético" y con respecto a las ITS lo hacen por medio de la aparición de los síntomas, esto demostrado en la respuesta que da una estudiante a la siguiente pregunta en un taller: ¿cuál podría ser el ciclo reproductivo del herpes genital, cuando este aún no genera úlceras en los genitales?, "Un ciclo lisogénico, ya que el virus permanece inactivo por cierto tiempo, hasta que un evento celular dispara el proceso nuevamente", de tal forma que reconocen, que por características como el ciclo reproductivo los virus pueden ser asintomáticos en un determinado momento, pero aun así tener infectada la célula hospedera.

Entendiendo que los estudiantes realizan una comprensión de la importancia de prevenir ITS, especialmente aquellas producidas por virus, fue necesario entablar un diálogo con ellos acerca de los métodos para prevenirlas, el condón es una de las primeras opciones propuestas por ellos,

relacionándose directamente con las afirmaciones que realizan Páez \& García (2015) y Raimundo \& Verdura (2010) del uso del condón como el método de prevención que prevalece en los adolescentes y en la población en general para evitar una TS.

Con respecto a otras estrategias

\begin{tabular}{|c|c|c|c|c|c|}
\hline & CONDÓN & $\begin{array}{c}\text { CHEQUEO } \\
\text { MÉDICO }\end{array}$ & $\begin{array}{c}\text { COMUNICACIÓN } \\
\text { CON LA PAREA }\end{array}$ & $\begin{array}{c}\text { LIMITAR No. DE } \\
\text { PAREAS SEXUALES }\end{array}$ & ABSTINENCIA \\
\hline $\mathbf{1}$ & $32,2 \%$ & $9.67 \%$ & $35.48 \%$ & $16.12 \%$ & $6.45 \%$ \\
\hline $\mathbf{2}$ & $41.93 \%$ & $19.35 \%$ & $19.35 \%$ & $16.12 \%$ & $9.67 \%$ \\
\hline $\mathbf{3}$ & $16.12 \%$ & $16.12 \%$ & $32.2 \%$ & $22.58 \%$ & $12.90 \%$ \\
\hline 4 & $3.22 \%$ & $41.93 \%$ & $9.67 \%$ & $35.48 \%$ & $12.90 \%$ \\
\hline 5 & $9.67 \%$ & $12.90 \%$ & $3.22 \%$ & $12.90 \%$ & $58.06 \%$ \\
\hline
\end{tabular}

Tabla 2. Enumere de 1 a 5 el ítem (comunicación con la pareja, condón, limitar número de parejas sexuales, chequeos médicos, y abstinencia) que usted considera tiene mayor importancia hasta el que tiene menor importancia en la prevención de ITS (siendo 1 el may or y 5 el menor)

de prevención a partir de una pregunta en el cuestionario final, los estudiantes consideran que los métodos más importantes para prevenir una ITS son la comunicación con la pareja y el uso del condón por encima de los demás (véase Tabla 2). Resaltan la buena comunicación con la pareja porque comprenden que el estar sano también involucra al otro, evidenciado en afirmaciones como: "Es importante estar sano para no contagiar al otro, "para cuidar mi cuerpo, mi organismo y que mi cuerpo este bien" y "Las ITS pueden acabar con la vida y afectar a las demás personas",

YO TE DIJE QUE USARAMOS CONDON PARA PREVENIR ENFERMEDADES PERO...

ZA CASO NE PUSISTE ATENCIÓN CUANDOTE HABLABA?

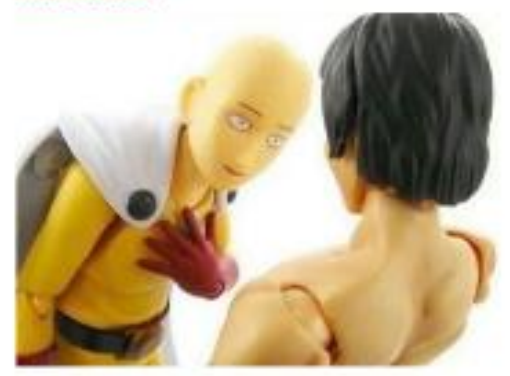

PRACTICA EL AMORA TU CUERPO CON HABITOE SANOE, PERO NO LE RINDAS

Imagen 5. Campana prev ención por un estudiante donde esto último se

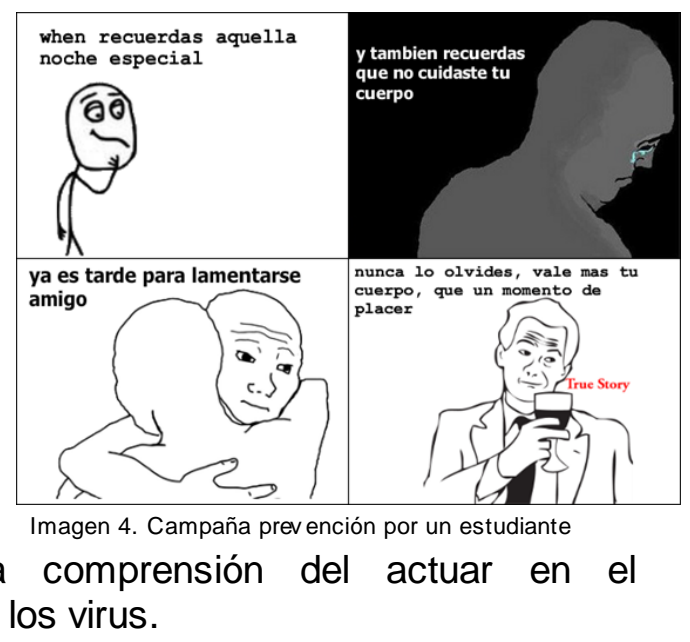
organismo de los virus.

Esto último, deja evidenciar que el estudiantado expone una importancia por el propio cuerpo y del otro (Véase imagen 4 y 5), lo que se relaciona con el modelo afectivo que proponen Rivera, Sepúlveda \& Camacho (2015), cuando plantean que cuando se aborda el tema de las ITS en el espacio de educación sexual, los estudiantes consideran aspectos que van más allá de lo biológico, como lo afectivo y lo social. Donde el 
Bio - grafía. Escritos sobre la Biología y su Enseñanza. ISSN 2027-1034

Edición Extraordinaria. p.p. 1263 - 1270

Memorias del IX Encuentro Nacional de Experiencias en Enseñanza de la Biología y la Educación Ambiental. IV Congreso Nacional de Investigación en Enseñanza de la Biología.

modelo afectivo hace referencia a una importancia por las relaciones humanas, en especial con la pareja, en el caso de esta investigación haciendo referencia a una preocupación por la salud sexual del otro.

\section{CONCLUSIÓN}

Partiendo del desarrollo conceptual de los virus los estudiantes logran señalar características particulares de estos organismos que se encuentran relacionadas con el ciclo reproductivo y especialmente con la morfología, lo que permite que ellos se aproximen a la comprensión del actuar de estos microorganismos en el cuerpo y lo que pueden generar en él, de manera que comprenden la importancia del cuidado de su salud sexual, en un aspecto como las ITS y las posibles estrategias a usar para ello, como el comunicarse con la pareja, limitar el número de parejas sexuales, realizar chequeos médicos y el uso del condón.

\section{BIBLIOGRAFÍA}

Antonio, M. \& Vallejo, Y. (2016). La enseñanza de la microbiología desde las prácticas de laboratorio en estudiantes de grado once, de un colegio en Bogotá. Revista Tecné, Episteme y Didaxis: TED. Año 2016, Número Extraordinario. 534-540

Boronat, R. \& López, J. (2014). Estudio de la transmisión de la infección del VIH en el laboratorio de educación secundaria. Revista Eureka sobre Enseñanza y Divulgación de las Ciencias 11(1), 94-99

Fonseca, G. (2015). El conocimiento profesional del profesor de biología: configuración desde la investigación- acción. Bio-grafia. Escritos sobres la biología y su enseñanza. Edición extraordinaria. 930-946

Meinardi, E., Revel, A., Godoy, E., Iglesias, M., Rodríguez, I., Plaza, M., \& Bonan, L. (2008). Educación para la Salud Sexual en la formación de profesores en Argentina. Ciência \& Educação 14. (2), 181-195

Mendoza, L., Arias, M., Pedroza, M., Micolta, P., Ramírez, A., Cáceres, C., López, D., Núñez, A. \& Acuña, M. (2012). Actividad sexual en adolescencia temprana: problema de salud pública en una ciudad colombiana. Revista chilena de obstetricia y ginecología 77(4), 271 - 279.

Páez, G. \& García, J. (2015). Categorías conceptuales de estudiantes de grado octavo sobre ETS luego de la implementación de una unidad didáctica desde el ABP. Biografía. Escritos sobre la Biología y su Enseñanza. ISSN 2027 Edición Extraordinaria. 1289-1298

Porlán, R. \& Martín, J. (1991). Un recurso para la investigación en el aula. Sevilla: Díada. Recuperado de: https://ariselaortega.files.wordpress.com/2013/11/4-porlanrafael-el-diario-del-profesor.pdf

Raimundo, M. \& Verdura, M. (2010). Conocimientos sobre el papiloma virus humano en una escuela secundaria de la ciudad de corrientes. Revista de Posgrado de la Vla Cátedra de Medicina. 
Bio - grafía. Escritos sobre la Biología y su Enseñanza. ISSN 2027-1034

Edición Extraordinaria. p.p. 1263 - 1270

Memorias del IX Encuentro Nacional de Experiencias en Enseñanza de la Biología y la Educación Ambiental. IV Congreso Nacional de Investigación en Enseñanza de la Biología.

Rivera, M., Sepúlveda, P. \& Camacho, J. (2015). Educación sexual más allá de lo biológico. Bio-grafía Escritos sobre la Biología y su enseñanza 9(16), 131-146.

Roa, P. \& Osorio, A. (2015). Problematización de la Educación Sexual: Reflexiones acerca de la sexualidad en la escuela Colombiana. Bio-grafía Escritos sobre la Biología y su enseñanza 9(16), 23-29

Rozo, J. (2011). TRABAJO PRÁCTICO: recurso que propicia el aprendizaje significativo sobre diversidad y ecología microbiana en estudiantes de grado cuarto $\left(4^{\circ}\right)$ del colegio Champagnat de Bogotá. Bio-grafía. Escritos sobre la biología y su enseñanza 4(6), 1-18.

Vasilachis, I., Ameigeras, A., Chenobilsky, L., Giménez, V., Mallimaci, F., Mendizábal, N., Neiman, G., Quaranta, G., \& Soneira, A. (2006). Estrategias de investigación cualitativa. Gedisa, editorial. 